\title{
Perspective, Awareness, and Behaviour towards Text-Neck among Medical Students of Majmaah University - A Cross Sectional Study
}

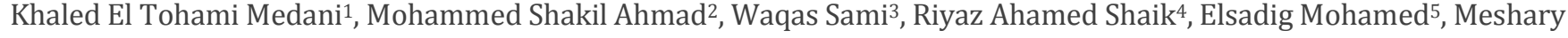 \\ Abdullah Alhammad ${ }^{6}$, Moath Mohameed S. Almutlaq ${ }^{7}$, Zaid A. M. Alodaini Alotiabi ${ }^{8}$, Faisal Hassan Alshammary ${ }^{9}$ \\ 1, 2, 3, 4, 5, Department of Community Medicine and Public Health, College of Medicine, Majmaah University, \\ Majmaah, Saudi Arabia. 6, 7,8,9 College of Medicine, Majmaah University, Majmaah, Saudi Arabia.
}

\section{ABSTRACT}

\section{BACKGROUND}

Smart devices are being extensively used for communication and entertainment purposes. When users spend long time suing these devices, it may lead to text neck syndrome. We wanted to assess perspective, awareness, and behaviour toward the text neck among medical students of Majmaah University.

\section{METHODS}

This is an observational institutional cross-sectional study which was conducted at Majmaah University in Majmaah city. The study included 229 medical college students from the $2^{\text {nd }}$ to $6^{\text {th }}$ year of the college. A pre-tested questionnaire was used to evaluate the students regarding knowledge, attitude, and practice with regard to text neck syndrome.

\section{RESULTS}

This study included 229 medical college students, $140(61.1 \%)$ of them had good knowledge, 77 (33.6 \%) of them had moderate knowledge, while only 12 (5.2\%) of them had poor knowledge. 125 (54.6\%) of them had a positive attitude, while 104 ( $45.4 \%$ ) of them had a negative attitude. Regarding the practice, there was a variation of answers which indicated moderate practice among the majority of them.

\section{CONCLUSIONS}

The development of technology, the increasing number of smart devices, the increasing number of users of these devices have led to increase in the number of patients of text neck syndrome. Our study shows that there was good knowledge, positive attitude, and moderate practice among these medical students toward this syndrome at Majmaah University.

\section{KEY WORDS}

Smart Devices, Medical Students, Text Neck, Majmaah University
Corresponding Author: Dr. Mohammad Shakil Ahmad, Assistant Professor Department of Community Medicine and Public Health, College of Medicine, Majmaah University,

Majmaah - 11952, Saudi Arabia.

E-mail:m.shakil@muedu.sa

DOI: $10.14260 / j e m d s / 2021 / 65$

How to Cite This Article: Medani KET, Ahmad MS, Sami W, et al. Perspective, awareness and behaviour towards text-neck among medical students of Majmaah university - a cross-sectional study. J Evolution Med Dent Sci 2021;10(05):294-298, DOI: 10.14260/jemds/2021/65

Submission 28-08-2020,

Peer Review 01-12-2020,

Acceptance 08-12-2020,

Published 01-02-2021.

Copyright (C) 2021 Khaled El Tohami Medani et al. This is an open access article distributed under Creative Commons Attribution License [Attribution 4.0 International (CC BY 4.0)] 


\section{BACKGROUND}

Smart devices are devices which are used for communication and entertainment purposes. It has been defined according to oxford as "the devices which have Internet access, and an operating system capable of running downloaded applications."1 For example, media, web access, and gaming, which allow smartphone users to have access to different aspects of the network and virtual reality. Additionally, it has multiple usability options for use which may make the users spend a long time while using their devices. The use of smart devices is in increasing due to a big evolution of technology, that allow the users to be capable of communicating with the others in a way other than by the direct voice like for example by using SMS, WhatsApp, and different social networks applications. ${ }^{2}$ In a previous couple of years, touch screens smartphones have replaced the majority of smart devices product because of its easy accessibility and it is plentiful, However, as many people making their head flexed in a forward position when using the smart devices, there is developing concern about the impact of Smart devices on musculoskeletal system among prolonged users of these devices which may increase the risk for developing some symptoms such as chronic neck pain and shoulder pain ${ }^{3}$, so increasing the time which spends on using the smart devices may lead to many health issues some of them are likely to have a negative effect which can affect millions of people all around the world, recently there is a new syndrome appeared which may affect the musculoskeletal system which called text neck syndrome.

Text Neck syndrome is a major public health problem in modern societies used to describe a repetitive stress syndrome caused by the exaggerated, forward position of the head due to using of smart devices such as mobile phones and laptops ${ }^{3}$. Some people especially young people spent averages of 5 and 7 hours per day with their heads are in a wrong position while they are reading or texting or even playing on their smart devices which most major risk factors for developing this syndrome 4 , according to ACA in 2015 a survey has been made in America shows that $83 \%$ of American adults own cell phones with nearly all of them sending and receiving text messages, the average of messages which has been sent and received were 41.5 messages for a day among each one of them.

The Pain which affects the neck, shoulder, and arms are widespread among various population groups. The presence of head and neck symptoms in association with using smart devices has been previously described. However, an article described that Excessive use of smart devices can create tension in the deep muscles causing nagging pain to sharp and severe upper back muscles. The changes in the normal cervical curve posture and its ligaments may lead to adapting to that wrong posture which can cause numbness in the hands, Headache, and also muscle ${ }^{5}$.

With a high risk of text neck, symptoms ${ }^{2}$ the degree of flexion is effected by Weight of the head and it is playing an important role in effecting on the neck and spinal cord during flexing for a long time like at 15 degrees the force on the neck around 27 pounds, at 30 degrees 40 pounds, at 45 degrees 49 pounds, and at 60 degrees 60 pounds and so on ${ }^{2}$, that lead to loss the natural curvature of spinal and may lead to some complications such as flattening of the spinal curve, disc compression, and muscle-nerve damage. Prevention and management include avoiding and limiting the activities on using smart devices such as mobile phones and laptops and take frequent breaks after 20 - 30 minutes of using the smart devices in addition to correcting the wrong posture by stand posture when the ears are ranged with the meddling of the shoulders, ${ }^{6}$ and there are other significant symptoms for text neck like headache and cervical pain ${ }^{7-9}$. The weight of the average head experts approximately $10-12$ pounds of force through the muscles of the neck which indicates mostly a healthy posture better than when the degree of head flexion is increased ${ }^{10}$. The present study was carried out to assess the perspective, awareness, and behaviour towards text-neck among the medical students of Majmaah University.

\section{METHODS}

An observational cross-sectional study was performed to study the perspective, awareness and behaviour towards textneck among the medical students of Majmaah University. The study was conducted among all medical students (229 students) studying in $2^{\text {nd }}$ year to the $6^{\text {th }}$ year at College of Medicine, Majmaah University, Majmaah, Saudi Arabia.

The data was collected through pre-tested, coded questionnaires. The questionnaire consisted of four parts, the first part consisted of demographic variables, second part was related to student's knowledge about text neck, third part was about evaluating their awareness and the last one was about their intention to protect themselves from text neck.

The data was entered and analysed by computer using IBM SPSS 25.0. Frequencies and percentages are reported for qualitative variables. Pearson Chi-square and Fisher Exact test were applied to assess the association between qualitative variables. A p-value of $<0.05$ was considered as statistically significant. Ethical approval was obtained from Ethics committee of health and basic medical and health research centre (BMHRC) of Majmaah University. Respondents participated in the study was on a voluntary basis and an informed consent was obtained. Confidentiality and anonymity of the subject were maintained throughout the study. All data were amalgamated to further reduce the potential for identification of the students.

\section{RESULTS}

Data was collected from 229 medical students of which (n = $171 ; 74.7 \%)$ were males and $(n=58 ; 25.3 \%)$ were females. Most of the students ( $\mathrm{n}=108 ; 47.2 \%$ ) were between the agegroup of $20-22$ years, followed by $(n=99 ; 43.2 \%)$ who belonged to the age-group of 23 - 25 years, below 20 years were ( $\mathrm{n}=19 ; 8.3 \%)$, whereas, only $1.3 \%$ were more than 25 years. Majority of the students ( $\mathrm{n}=63 ; 27.5 \%)$ were studying in $2^{\text {nd }}$ year, followed by $(\mathrm{n}=51 ; 22.3 \%)$ in $3^{\text {rd }}$ year, $(\mathrm{n}=35$; $15.3 \%)$ in $4^{\text {th }}$ year, $(n=49 ; 21.4 \%)$ in $5^{\text {th }}$ year, and $(n=31$; $13.5 \%)$ were studying in the $6^{\text {th }}$ year. The major bulk of students ( $\mathrm{n}=84 ; 36.7 \%)$ were using the smart devices for 3 6 hours per day, around one-quarter students were using them 
for more than 6 hours per day, and $(n=69 ; 30.1 \%)$ were using them for less than 3 hours per day. The results are presented in Table 1.

\begin{tabular}{|c|c|c|c|}
\hline & Variables & $n=229$ & Percent \\
\hline \multirow[t]{2}{*}{ Gender } & Male & 171 & 74.7 \\
\hline & Female & 58 & 25.3 \\
\hline \multirow{4}{*}{ Age } & $<20$ & 19 & 8.30 \\
\hline & $20-22$ & 108 & 47.2 \\
\hline & $23-25$ & 99 & 43.2 \\
\hline & $>25$ & 03 & 1.30 \\
\hline \multirow{5}{*}{ Academic Year } & $2^{\text {nd }}$ & 63 & 27.5 \\
\hline & $3^{\text {rd }}$ & 51 & 22.3 \\
\hline & $\begin{array}{l}4^{\text {th }} \\
5^{\text {th }}\end{array}$ & 35 & 15.3 \\
\hline & $5^{\text {th }}$ & 49 & 21.4 \\
\hline & & 31 & 13.5 \\
\hline \multirow{3}{*}{$\begin{array}{c}\text { Duration of Using } \\
\text { Their Smart Devices } \\
\text { Daily }\end{array}$} & Less than $3 \mathrm{~h} /$ day & 69 & 30.1 \\
\hline & $3-6 h /$ day & 84 & 36.7 \\
\hline & More than $6 \mathrm{~h} /$ day & 76 & 33.2 \\
\hline \multicolumn{4}{|c|}{$\begin{array}{l}\text { Table 1. Demographic Characteristics and Duration of Using } \\
\text { Smartphones }\end{array}$} \\
\hline
\end{tabular}

Results presented in Table 2 showed that most of the students ( $\mathrm{n}=163 ; 71.2 \%$ ) did not know about the negative impact of using smart devices (text-neck syndrome). Those who knew about the text-next syndrome were $(n=66 ; 28.8 \%)$ of which most of the source of knowledge was from the "social media ( $\mathrm{n}=27 ; 40.9 \%)$ ", followed by "public media ( $=17$; $25.75 \%)$ ", "other sources ( $\mathrm{n}=20 ; 30.3 \%)$ )" and "doctor and seminar ( $n=1 ; 1.5 \%)$ " respectively. More than two-quarter of the students ( $\mathrm{n}=195 ; 85.2 \%$ ) knew that the cause of the text neck is due to the wrong posture and only $18 \%$ had awareness about using the smart devices in the right position. In addition, majority of them ( $\mathrm{n}=176 ; 76.9 \%)$ stated that the right position of head when using the smart devices is at $0^{0}$, followed by those who stated $15^{\circ}(\mathrm{n}=35 ; 15.3 \%), 30^{\circ}(\mathrm{n}=8$; $3.5 \%), 45^{\circ}(\mathrm{n}=4 ; 1.7 \%)$ and $60^{\circ}(\mathrm{n}=6 ; 2.6 \%)$ respectively. More than two-quarter of the students stated that they are aware of bending the head when using smartphones $(n=173$; $75.5 \%)$. Overall, more than $50 \%$ of the students had an awareness of text-neck syndrome.

\begin{tabular}{|ccc|}
\hline Awareness about test-neck & Items & N (\%) \\
syndrome & No & $163(71.2)$ \\
& Yes & $66(28.8)$ \\
Awareness about the relation & No & $34(14.8)$ \\
between the wrong posture and & Yes & $195(85.2)$ \\
text-neck syndrome & $0^{0}$ & $176(76.9)$ \\
Awareness regarding the right & $15^{0}$ & $35(15.3)$ \\
position (degree) of the head when & $30^{0}$ & $8(3.5)$ \\
using the smart devices. & $45^{0}$ & $4(1.7)$ \\
& $60^{0}$ & $6(2.6)$ \\
Awareness about bending the head & No, I am not aware & $56(24.5)$ \\
when using smart devices. & Yes, I am aware & $173(75.5)$ \\
Awareness About Using the Smart & No & $188(82.1)$ \\
Devices in Right Position? & Yes & $41(17.9)$ \\
Overall awareness of text-neck & Positive & $125(54.6)$ \\
syndrome & Negative & $104(45.4)$ \\
\hline Table 2. Awareness about What Text-Neck Syndrome Means \\
and the Sources of This Knowledge
\end{tabular}

\begin{tabular}{|c|c|c|}
\hline \multicolumn{2}{|c|}{ Variables } & $\mathbf{N}(\%)$ \\
\hline \multirow{5}{*}{$\begin{array}{l}\text { The Preferred Position of The Head } \\
\text { When Using the Smart Devices }\end{array}$} & $0^{0}$ & $12(5.2)$ \\
\hline & $15^{0}$ & $40(17.5)$ \\
\hline & $30^{\circ}$ & $89(38.9)$ \\
\hline & $45^{0}$ & $72(31.4)$ \\
\hline & $60^{\circ}$ & $16(7.0)$ \\
\hline \multirow{5}{*}{$\begin{array}{l}\text { Perspective Regarding the Most } \\
\text { Common Sign or Symptom of } \\
\text { Text-Neck Headache }\end{array}$} & Neck Headache & $53(23.1)$ \\
\hline & Neck pain or discomfort & $114(49.8)$ \\
\hline & Neck Muscle spasm & 35 (15.3) \\
\hline & Hands numbness & $11(4.8)$ \\
\hline & Neck tenderness & $16(7.0)$ \\
\hline \multirow{3}{*}{$\begin{array}{l}\text { Frequency of Signs and Symptoms } \\
\text { Per Day Among the Students. }\end{array}$} & Less than 3 times / day & $187(81.7)$ \\
\hline & 3 - 5 times / day & $33(14.4)$ \\
\hline & More than 5 times / day & $9(3.9)$ \\
\hline \multirow{5}{*}{$\begin{array}{c}\text { Relieving Methods Among Students } \\
\text { when They Have Neck Pain After } \\
\text { Using Smart Devices for a Long } \\
\text { Time Using smart devices with } \\
\text { right }\end{array}$} & head nosition & $64(279)$ \\
\hline & Put warm water & $18(7.9)$ \\
\hline & Go to hospital & $10(4.4)$ \\
\hline & Massage and relaxation & $88(38.4)$ \\
\hline & Nothing & $49(21.4)$ \\
\hline \multicolumn{3}{|c|}{ Action That the Students Do when } \\
\hline \multirow{2}{*}{\multicolumn{2}{|c|}{$\begin{array}{l}\text { Recognize That They Are in the Correct it to the healthy posture } \\
\text { Wrong Posture During Using Their } \begin{array}{c}\text { Continue using smart devices } \\
\text { Smart Devices }\end{array}\end{array}$}} & $207(90.4)$ \\
\hline & & $22(9.6)$ \\
\hline \multirow{3}{*}{$\begin{array}{l}\text { Overall perspective Toward Text } \\
\text { Neck Syndrome }\end{array}$} & Poor Knowledge & $12(5.2)$ \\
\hline & Moderate Knowledge & $77(33.6)$ \\
\hline & Good Knowledge & $140(61.1)$ \\
\hline \multicolumn{3}{|c|}{$\begin{array}{c}\text { Table 3. Perspective towards Text-Neck Syndrome } \\
\text { and Its Signs \& Symptoms }\end{array}$} \\
\hline
\end{tabular}

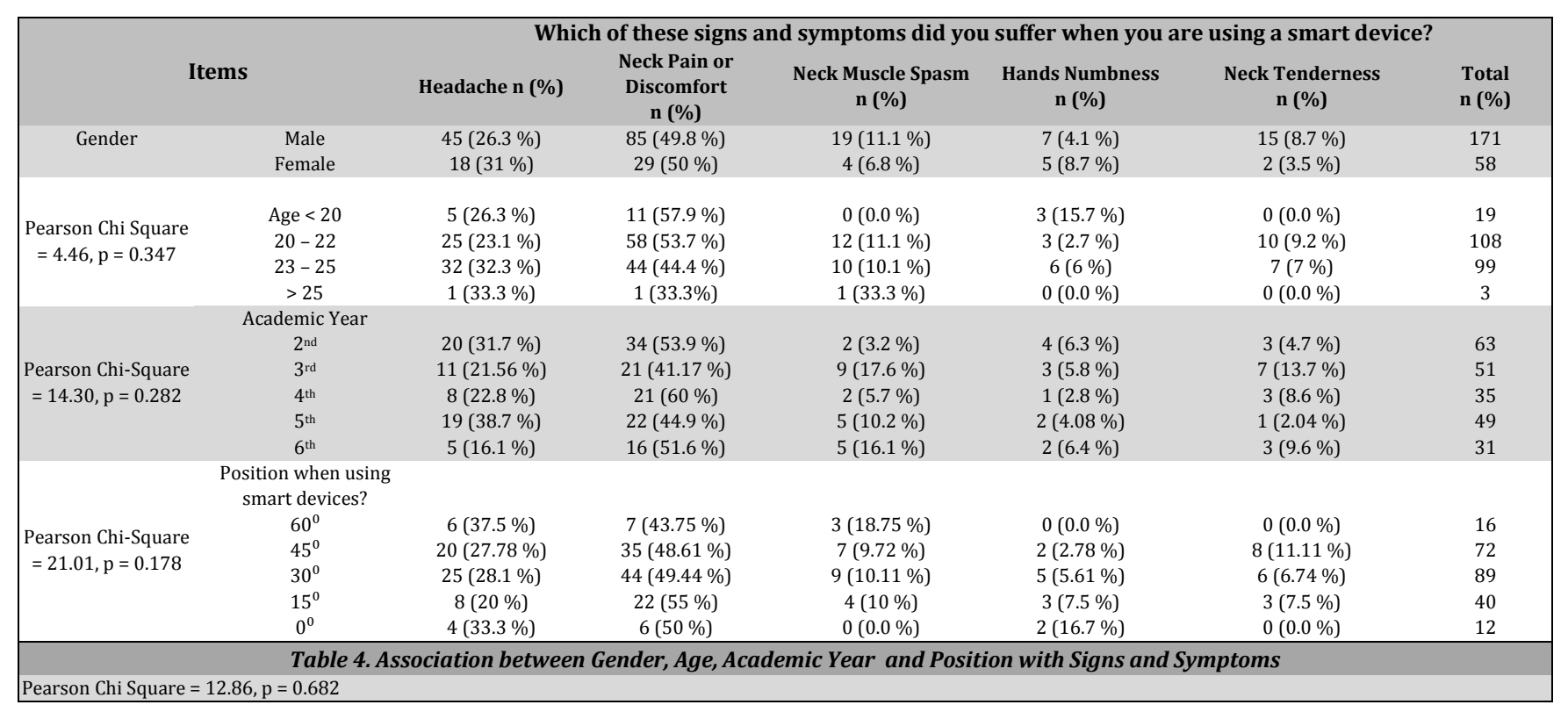


Results presented in Table 4 showed that no significant association was observed between the signs \& symptoms being suffered while using the smart devices with gender $(\mathrm{p}=$ $0.347)$, age $(p=0.282)$, academic year $(p=0.178)$ and position when using the smart devices ( $\mathrm{p}=0.682)$.

Majority of the students $(n=89 ; 38.9 \%)$ preferred to use their smart devices at $30^{\circ}$, whereas, $(n=72 ; 31.4 \%),(n=40$; $17.5 \%),(n=16 ; 7 \%)$ and $(n=12 ; 5.2 \%)$ preferred to use their smart devices at $45^{\circ}, 15^{\circ}, 60^{\circ}$ and $0^{\circ}$ respectively. The most common sign \& symptom of text-neck reported by the students was "neck pain and discomfort ( $\mathrm{n}=114 ; 49.8 \%)$ ), followed by "headache ( $\mathrm{n}=53 ; 23.1 \%)$ ", "neck muscle spasm ( $\mathrm{n}=35 ; 13.3 \%$ )", "neck tenderness ( $=16 ; 7 \%$ )" and "hand tenderness $(\mathrm{n}=11 ; 4.8 \%)$. . Around $82 \%$ of the students had these signs \& symptoms less than 3 times / day. Around $90 \%$ of the students corrected their posture after realizing having the wrong posture while using the smart devices. Massage and relaxation were the most reported $(n=88 ; 38.4 \%)$ relieving method when having pain after using the smart devices, it was followed by correcting the head position ( $\mathrm{n}=64 ; 27.9 \%$ ), placing warm water $(\mathrm{n}=18 ; 7.9 \%)$ and going to the hospital ( $\mathrm{n}=10 ; 4.4 \%$ ). More than $50 \%$ of the students had good knowledge towards text-next syndrome, $(n=77 ; 33.6 \%)$ had moderate knowledge and only $5.2 \%$ had poor knowledge. Results are presented in Table 3.

\section{DISCUSSION}

In this study knowledge about the terminology (text neck syndrome) is poor (71.2\%), because it was recently applied, the general knowledge about a negative impact on the neck after excessive use of the smart device is good. Besides, the attitude is positive while the practice is bad (only $5.2 \%$ of the students use their devices with their heads 0 degrees). It was noted that the overall level of knowledge was found to be good among the students (61.1\%), moderate in (33.6\%), and poor in (5.2\%). Good knowledge noted in medical students can be because of awareness of excessive use of smart devices on neck pain. About the attitude, it was positive in $54.6 \%$ of the students and acceptable in (45.4\%) of them, the most positive attitude was observed when the students correct the wrong posture after recognizing that they are in the wrong head position. The results of the students' practice correspond with a recently published study done by Sojeong lee, Hwayeong Kang, and Gwanseop shin $2014 .{ }^{8}$

A cross-sectional study was done in Aljouf University Kingdom of Saudi Arabia in 396. 212 respondents show that the most commonly reported complaint was neck pain due to smart devices and 251 of them had a headache and it is the second most common symptom which occurred to them after the neck pain. ${ }^{6}$

A study done by Sojeong Lee, Hwayeong Kang \& Gwanseob in 2014 among 18 participants which they are using smart devices for texting, using internet and video watching with flexing their neck for a long time while sitting and standing, It found that the majority of participants maintained head flexion of $33-45^{\circ}$ and indicates that the angle of flexion was larger for text message than for other activities, and also the angle larger while sitting than while standing. ${ }^{10}$

One study showed that the majority of the participants maintained their head flexed in about $30-45^{\circ}$ which was found to be similar to our study which is $30^{\circ}$ among (38.9\%) and $45^{\circ}$ among (31.4\%) of the students. And the most common symptom which reported from a study done in Las Vegas among 412 participants is neck pain( $84.6 \%$ ), 11 in addition to a study done in China among 2575 which shows that the most common symptom is neck pain in ( $40 \%$ ) of them. ${ }^{12}$

Whereas another study done in Thailand said that "Text Neck has become a global problem that affects millions of people all around the world". The research tool had done by using the internet, the survey conducted upon 642 responses shows that $62.3 \%$ of responses experienced pain at the neck and shoulder when they working on the computer or other smart devices According to our study regarding the duration of using smart devices, we observed that the time which spends during using smart devices was higher than that in South Korea which was found to be about 2 hours among $(66.96 \%)$ of them. ${ }^{13}$

A study at U1 University in Chungbuk, South Korea has done on the impacts of posture on neck flexion angle while utilizing a Smartphone according to duration. The subjects were 16 healthy young students in their 20s. This study was done to examine changes in the neck flexion angle according to posture while utilizing a smartphone and the duration of smartphone utilization, the result showed that Neck flexion is affected by the position while utilizing a smartphone 14 . Another study at King Saud University, Kingdom of Saudi Arabia done to know the association between smartphone use addiction and neck disability, showed the close relationship between the addiction of smartphone use and various degree of neck problems among the participants. ${ }^{15}$

A cross-sectional study was carried out in Brazil in 18 to 21-year-old students from high school using the Young Spine Questionnaire. Neck posture was assessed by student's selfperception and by physiotherapists during texting message tasks on mobile phones. On analysis no association between neck postures, assessed by self-perception, and neck pain, nor between neck posture, assessed by physiotherapists' judgment, and neck pain. ${ }^{16}$ Fadi Al-Hadidi et al (2019), conducted an observational study on 200 university students in Jordan noted a significant difference in mobile usage among different faculty students and more usage in female students compared to male students. There was no significant association of mobile phone usage with the severity of neck pain. ${ }^{17}$

\section{CONCLUSIONS}

The development of technology, the increasing number of smart devices, the increasing number of users of these devices have led to increase in the number of patients of text neck syndrome. Our study shows that there was good knowledge, positive attitude, and moderate practice among these medical students toward this syndrome at Majmaah University. 


\section{Recommendation}

Health education and programs that increase the awareness of the risks of the smart device use should be started. Also, use of an application on mobile phones that alerts a person if he has bent his neck can be very helpful.

\section{Limitations}

This was a self-questionnaire-based study, and the presence of student's bias cannot be ruled out which could impact the results of the study. Due to time limitations, we could not include a greater number of the students in this study.

Data sharing statement provided by the authors is available with the full text of this article at jemds.com.

Financial or other competing interests: None.

Disclosure forms provided by the authors are available with the full text of this article at jemds.com.

\section{REFERENCES}

[1] https://en.oxforddictionaries.com/definition/smartpho ne

[2] Vate-U-Lan P. Text neck epidemic: a growing problem for smart phone users in Thailand. The Twelfth International Conference on eLearning for Knowledge-Based Society, 2015 December 17.

[3] Jawad F, Mohamad YF, Youssef F. Musculoskeletal neck pain in children and adolescents: risk factors and complications. Surg Neurol Int 2017;8:72.

[4] http://text-neck.com/meet-dr.-fishman.html

[5] Elizabeth B. How texting can be a pain in the neck? NZ Herald, 2010 November 19.

[6] Bader KA, Santosh RP. Mobile phone head and neck pain syndrome: proposal of a new entity. OHDM 2015;14(5):313-7.
[7] https://www.ansellchiropractic.com.au/text-neck/

[8] Sojeong L, Hwayeong K, Gwanseop S. Head flexion angle while using a smartphone. Ergonomics 2015;58(2):2206.

[9] https://www.spine-health.com/blog/modern-spineailment-text-neck

[10] Lee HJ. Neck pain and functioning in daily activities associated with smartphone usage. Journal of Korean Physical Therapy 2016;28(3):183-8.

[11] Blair B, Gama M, Toberman M. Prevalence and risk factors for neck and shoulder musculoskeletal symptoms in users of touch-screen tablet computers. UNLV Theses, Dissertations, Professional Papers, and Capstones, University Libraries, 2015.

[12] Shan Z, Deng G, Li J, et al. Correlational analysis of neck/shoulder pain and low back pain with the use of digital products, physical activity, and psychological status among adolescents in Shanghai. PLoS One 2013;8(10):e78109.

[13] Sunil N, Ifthikar AUT, Mathew A. Text neck syndrome systematic review. Imperial Journal of Interdisciplinary Research 2017;3(7):141-8.

[14] Lee SY, Lee DH, Han SK. The effects of posture on neck flexion angle while using a smartphone according to duration. J Korean Soc Phys Med 2016;11(3):35-9.

[15] AlAbdulwahab SS, Kachanathu SJ, AlMotairi MS. Smartphone use addiction can cause neck disability. Musculoskeletal Care 2017;15(1):10-12.

[16] Damasceno GM, Sa Ferreira A, Nogueira LAC, et al. Text neck and neck pain in 18-21 year-old young adults. European Spine Journal 2018;27(6):1249-54.

[17] Al-Hadidi F, Bsisu I, AlRyalat SA, et al. Association between mobile phone use and neck pain in university students: a cross-sectional study using a numeric rating scale for evaluation of neck pain. PLoS One 2019;14(5):e0217231. 